\title{
Bacterial Communities Involved in Soil Formation and Plant Establishment Triggered by Pyrite Bioweathering on Arctic Moraines
}

\author{
Francesca Mapelli - Ramona Marasco - Agostino Rizzi • \\ Franco Baldi • Stefano Ventura • Daniele Daffonchio • \\ Sara Borin
}

Received: 16 June 2010 / Accepted: 28 September 2010/Published online: 16 October 2010

(C) Springer Science+Business Media, LLC 2010

\begin{abstract}
In arctic glacier moraines, bioweathering primed by microbial iron oxidizers creates fertility gradients that accelerate soil development and plant establishment. With the aim of investigating the change of bacterial diversity in a pyrite-weathered gradient, we analyzed the composition of the bacterial communities involved in the process by sequencing 16S rRNA gene libraries from different biological soil crusts (BSC). Bacterial communities in three BSC of different morphology, located within $1 \mathrm{~m}$ distance downstream a pyritic conglomerate rock, were significantly diverse. The glacier moraine surrounding the weathered site showed wide phylogenetic diversity and high evenness with 15 represented bacterial classes, dominated by Alphaproteo-
\end{abstract}

Electronic supplementary material The online version of this article (doi:10.1007/s00248-010-9758-7) contains supplementary material, which is available to authorized users.

F. Mapelli $\cdot$ R. Marasco $\cdot$ D. Daffonchio $\cdot$ S. Borin $(\square)$

Dipartimento di Scienze e Tecnologie Alimentari

e Microbiologiche, Università degli Studi di Milano,

Via Celoria 2,

20133 Milan, Italy

e-mail: sara.borin@unimi.it

\section{A. Rizzi}

Istituto per la Dinamica dei Processi Ambientali, CNR,

Via Mangiagalli 34,

20133 Milan, Italy

F. Baldi

Dipartimento di Scienze Ambientali,

Università di Venezia "Ca' Foscari",

30121 Venice, Italy

S. Ventura

Istituto per lo Studio degli Ecosistemi, CNR,

50019 Sesto Fiorentino, Italy bacteria and pioneer Cyanobacteria colonizers. The bioweathered area showed the lowest diversity indexes and only nine bacterial families, largely dominated by Acidobacteriaceae and Acetobacteraceae typical of acidic environments, in accordance with the low $\mathrm{pH}$ of the BSC. In the weathered BSC, iron-oxidizing bacteria were cultivated, with counts decreasing along with the increase of distance from the rock, and nutrient release from the rock was revealed by environmental scanning electron microscopy-energy dispersive X-ray analyses. The vegetated area showed the presence of Actinomycetales, Verrucomicrobiales, Gemmatimonadales, Burkholderiales, and Rhizobiales, denoting a bacterial community typical of developed soils and indicating that the lithoid substrate of the bare moraine was here subjected to an accelerated colonization, driven by iron-oxidizing activity.

\section{Introduction}

Primary succession is defined as the changes over time in biological communities on newly inhabited substrates [1]. Many studies described the process of plant primary succession [2, 3], but few described the mechanisms driving the first stages of the colonization of a barren substrate, before plant establishment. Microbes have a key role in the process of primary succession in terrestrial habitats, with an active role in element cycling, contributing to soil development and fertility, and to plant establishment. Moreover, biological weathering of rock is an important process that maintains a continuous supply of inorganic nutrients for plants in barren environments $[4,5]$.

Newly exposed glacial moraines are increasing due to global warming and consequent glacier retreat [6]. Moraines constitute ideal sites to study primary succession, where soil 
development from the mineral proto-soil released by the glacier can be studied along spatial gradients moving away from the glacier forefront. Hodkinson et al. [3] characterized a chronosequence in the foreland of the Midtre Lovénbreen glacier in the High Arctic region (Svalbard islands, $78^{\circ} 53^{\prime} \mathrm{N}$ ). Along the chronosequence, covering 2,000 years of ecosystem development following glacial regression, plant establishment and soil development were demonstrated to increase for the first 100 years after the retreat. Between 100 and 2,000 years since exposition from ice cover, plant species diversity did not increase, and soil development was similar [3]. A succession in soil bacterial communities, analyzed by T-RFLP of 16S rRNA gene, was demonstrated to occur in the Midtre Lovénbreen glacier, with a significant change in population structure along the chronosequence [7]. Very few works nevertheless analytically described the microbial succession along glacier forefronts. Successions of communities of early colonizers, dominated by Cyanobacteria, followed by typical soil bacterial phylotypes have been described, occurring in a large time interval during glacial regression in several glacier forefronts [8-12].

Recently, Borin et al. [13] characterized a series of sites in the moraine of the Midtre Lovénbreen glacier, estimated to have been released by the glacier less than 30 years ago. In these sites, conglomerate rocks rich in pyrite $\left(\mathrm{FeS}_{2}\right)$ micro-nodules showed red weathering biological soil crust (BSC) strips downstream the rocks, with low $\mathrm{pH}$ and high content of iron oxides. At the border of the red strip, green BSC strips were observed with a blooming vegetation of mosses and vascular plants that in the surrounding gray moraines are found only in advanced stages of the succession. Geochemical, biochemical, and microbiological characterization of these sites demonstrated that chemolithoautotrophic iron-sulfur oxidation of pyrite contained in the rock triggered early soil formation and promoted primary colonization by typical moraine mosses and vascular plants, such as the species Bryum sp., Ditricum flexicaule, and Saxifraga oppositifolia. The rock pyrite weathering is mediated by the chemolithotrophic Acidithiobacillus ferrooxidans, which produces $\mathrm{H}_{2} \mathrm{SO}_{4}$ and iron oxides due to sulfide and reduced iron oxidation. The generated $\mathrm{pH}$ gradient corresponded to fertility gradient, where water retention, cation exchange capacity, and nutrient availability were increased. This constituted a novel and previously unrecognized soil genesis and vegetation development model, where the proximity of the iron/sulfur-based chemolithoautotrophic activity in the red strip and the cyanobacterial photoautotrophic activity in the surrounding grey moraine allowed the establishment of an oasis of life at the border between the two areas, with an enhanced plant colonization [13].

In the present work, we analytically described the diversity and composition of the bacterial communities inhabiting BSC present in the area, only briefly presented in the previous multidisciplinary manuscript [13]. The aim of this work was to understand the role and dynamics of bacterial communities in the time-independent development of this particular ecosystem.

\section{Materials and Methods}

\section{Sampling}

Superficial soil crusts were collected from the MidtreLovéenbreen glacier (Ny Álesund, Svalbard) on sites ML-RS1 and ML-RC1 above a pyritic rock showing a weathering downstream strip with intensely vegetated areas at the border [13] (Supplementary online material, Fig. S1). Samples were collected with a sterile spatula along parallel transects. At site ML-RS1, two transects were studied, A and $\mathrm{B}$, located, respectively, 5 and $23 \mathrm{~cm}$ downstream the rock [13].

\section{SEM-EDX and ESEM-EDX Analysis}

Shiny thin sections of stone were visualized by a scanning electron microscope (Oxford, mod. STEREOSCAN 360) equipped with LaB6 filament. EDX analyses were performed with a link microprobe (Oxford, EDS) with acceleration tension $20 \mathrm{kv}$ and $25 \mathrm{~mm}$ working distance. Air-dried intact BSC samples were analyzed by environmental scanning electron microscopy-energy dispersive $\mathrm{X}$-ray (ESEM-EDX) spectroscopy. Samples were visualized by a scanning electron microscope (FEI Quanta mod. 200, Eindhoven, Netherlands) at an acceleration voltage of $25 \mathrm{kV}$ to determine elements in soil particle surface (triplicate) at 1.0 and 0.1 bar after $100 \mathrm{~s}$ scanning. Mean concentrations and standard deviations of each element were calculated from three random determinations with an approximate error of $1 \%$. The X-ray beam was $4 \mathrm{~mm}$ wide and penetrated to a depth of $2 \mu \mathrm{m}$.

\section{Iron-Oxidizing Bacteria Counts}

Most probable number-based counts of autotrophic ironoxidizing bacteria were performed on BSCs from site ML-RC1 that remained undisturbed after extensive multidisciplinary sampling of site ML-RS1. Soil crusts were aseptically collected, stored at $4^{\circ} \mathrm{C}$ during transporting to the laboratory, and inoculated $(1 \% w / v)$ in decimal serial dilutions in modified $9 \mathrm{~K}$ medium [14] supplemented with reduced iron sulfate in $3 \mathrm{ml}$ microtiter plates. After 4 weeks incubation at $15^{\circ} \mathrm{C}$, growth was positively scored when a rusty precipitate was observed in the wells, and bacterial cells were visible by microscope observation. 
16S rRNA Gene Libraries Construction

Samples RedA and RedB from the weathered area, transects A and B, respectively, Green A and GreenB from the same transects in the vegetated area, and GreyA and GreyB from the same transects in the external moraine area were chosen for $16 \mathrm{~S}$ rRNA clone library screening, after an initial screening of a larger set of samples by ARISA fingerprinting [13].

The almost complete bacterial 16S rRNA genes were amplified from the total DNA extracted from BSC samples as previously described [13]. PCR products were ligated into TOPO-TA cloning vector (Invitrogen s.r.l. Milan, Italy) and transfected into Escherichia coli JM 109 cells according to the manufacturer's instructions. One hundred white colonies containing recombinant plasmids were randomly picked from each library and grown in Luria-Bertani (LB) plates containing $100 \mu \mathrm{g} / \mathrm{ml}$ of ampicillin, $40 \mu \mathrm{g} / \mathrm{ml}$ of X-gal, and $0.5 \mathrm{mM}$ of IPTG at $37^{\circ} \mathrm{C}$ overnight. All the recombinant colonies have been inoculated in LB broth containing $100 \mu \mathrm{g} / \mathrm{ml}$ of ampicillin and $15 \% v / v$ of glycerol and incubated at $37^{\circ} \mathrm{C}$ overnight. Inserts were amplified using $2 \mu \mathrm{l}$ of cell culture as template and M13F (-20)/M13R primers in the following $\mathrm{PCR}$ reaction: initial denaturation at $94^{\circ} \mathrm{C} \times 5 \mathrm{~min}$, followed by 35 cycles at $94^{\circ} \mathrm{C} \times 1 \mathrm{~min}, 55^{\circ} \mathrm{C} \times$ $1 \mathrm{~min}, 72^{\circ} \mathrm{C} \times 1 \mathrm{~min} 30 \mathrm{~s}$, and by a final extension step at $72^{\circ} \mathrm{C}$ for $10 \mathrm{~min}$. Ninety of the clones containing the expected amplicon of $1.6 \mathrm{~Kb}$ have been partially sequenced (PRIMM, Italy). Sequences were edited in Chromas lite 2.01 (http:// www.technelysium.com.au) and subjected to BLAST search (http://blast.ncbi.nlm.nih.gov/Blast.cgi).

\section{Nucleotide Sequence Accession Numbers}

The partial 16S rRNA gene sequences $800-850$ bp long retrieved from the clone libraries have been deposited in GeneBank under accession numbers AM 940440 to AM 940936.

\section{Phylogenetic Analyses}

The CHIMERA_CHECK program available from the Ribosomal Database Project (http://rdp8.cme.msu.edu/cgis/ news.cgi) was used to exclude the presence of chimeric sequences. 16S rRNA gene sequences were aligned using the ClustalX software [15], and the output file was used to define operational taxonomic units (OTUs) and lineage per time plots using DOTUR [16]. A quantitative matrix was created basing on the absence/presence of each polymorphic OTU calculated at $95 \%$ nucleotide similarity, and detrended principal coordinate analysis has been performed with the MVSP software (Kovach Computing Services, UK). Data scored were detrended, and no species weighting was applied. The number of axes to be extracted was calculated by Gittma-Kaiser's familiar eigenvalue rule [17]. Principal component analysis was performed on the same matrix with the NTSYS pc version 2.01 software (Applied Biostatistics Inc.).

\section{Diversity Analyses}

Number of taxa, Shannon-Weaver, and Evenness indexes of the OTUs, defined at $95 \%$ of similarity, have been calculated using the PAST software [18]. Library coverage was calculated for each library using the equation $C=\left[1-\left(n_{1} / N\right)\right] \times 100$, where $n_{1}$ is the number of singleton OTUs, and $N$ is the total number of clones in the library. To compare the six $16 \mathrm{~S}$ rRNA gene libraries, the $\int$-Libshuff analysis has been applied using the software available at http://whitman.myweb.uga. edu/libshuff.html [19].

\section{Results}

16S rRNA Gene Libraries and Diversity Indexes

Six libraries of bacterial 16S rRNA gene of 90 clones each have been screened, obtained from BSCs of (1) the weathered area above the pyritic stone (libraries RedA and RedB), (2) the surrounding moraine (libraries GreyA and GreyB), and (3) the vegetated area at the border between them (libraries GreenA and GreenB). The libraries have been compared by a statistical shuffling approach. $\int$-Libshuff analysis [19] demonstrated that the three areas are colonized by significantly diverse bacterial communities. $\int$-Libshuff applied on replicated samples collected in each area at a distance of less than $20 \mathrm{~cm}$ (transects A and B) showed significant inter-sample variability in the vegetated area and in the surrounding moraine. On the contrary, libraries from the weathered area below the stone were not significantly diverse $(p<0.05)$.

OTUs were defined by the alignment of all the sequences at genus level, basing on $95 \%$ nucleotide similarity $\left(\mathrm{OTU}_{95}\right)$. The weathered area demonstrated an average of $25 \mathrm{OTU}_{95}$, while in the vegetated area and the surrounding moraines, biodiversity was higher with, respectively, 54 and $58 \mathrm{OTU}_{95}$. The diversity indexes based on the relative abundance of each $\mathrm{OTU}_{95}$ in the libraries were calculated and reported in Table 1. RedA and RedB libraries showed the lowest values of both Shannon index and Evenness, whereas the vegetated area demonstrated diversity indexes in the same range of the surrounding moraines. Detrended correspondence analyses (DCA) of a matrix constituted by $\mathrm{OTU}_{95}$ relative abundance reported that the bacterial community colonizing the BSC in the weathered area was strongly peculiar, while the vegetated 
Table 1 Diversity indexes and coverage calculated for the six 16S rRNA clone libraries

Sequences have been grouped in OTUs based on nucleotide similarity. Subscripts report the percentage of similarity considered for OTU definition

\begin{tabular}{lcccccc}
\hline & RedA & RedB & GreenA & GreenB & GreyA & GreyB \\
\hline Taxa $_{95}$ & 29 & 20 & 64 & 44 & 67 & 48 \\
Shannon index $_{95}$ & 2.878 & 2.429 & 4.020 & 3.400 & 4.032 & 3.564 \\
Evenness $_{95}$ & 0.613 & 0.567 & 0.871 & 0.681 & 0.841 & 0.735 \\
\% Coverage $_{95}$ & 83 & 91 & 46 & 69 & 39 & 64 \\
\% Coverage 97 & 80 & 88 & 38 & 67 & 32 & 60 \\
\% Coverage $_{99}$ & 76 & 83 & 29 & 64 & 24 & 49 \\
\hline
\end{tabular}

BSC and the surrounding moraine were similar, differentiated only on axis 1 of DCA plot (Fig. 1). The results were also confirmed by a different ordination method (principal component analysis, data not shown).

Lineage per time plots (Fig. 2) were in accordance with diversity indexes. Plots of the weathered area demonstrated a steep initial slope, similar to what was featured in young undeveloped moraine soils [9], indicating that this site is colonized by many individual phylotypes very closely related. In the vegetated area and the surrounding moraine, lineage per time plots were less steep, indicating that the bacterial communities in these sites had greater diversity at higher phylogenetic ranks. This was confirmed by coverage value calculation (Table 1), which reported that 90 clones sized libraries were enough to explore in the weathered area up to $91 \%$ of the total bacterial diversity at genus level $\left(\mathrm{OTU}_{95}\right)$ and up to $88 \%$ at species level $\left(\mathrm{OTU}_{97}\right)$, decreasing to $83 \%$ at subspecies level $\left(\mathrm{OTU}_{99}\right)$. On the contrary, the high diversity of the vegetated area and the surrounding moraines was not sufficiently described by this clone size libraries, even at genus level (maximum 69\% coverage for $\mathrm{OTU}_{95}$ ).

\section{Phylogenetic Analyses}

Detailed composition of the bacterial communities inhabiting BSC on the weathered area, the vegetated area, and the surrounding moraine has been determined by identifying the phylogenetic position of the 16S rRNA gene sequences

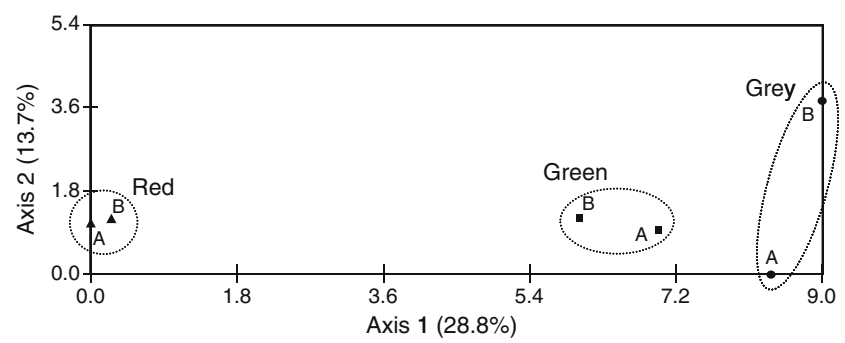

Figure 1 Detrended correspondence analysis applied on the quantitative matrix reporting $\mathrm{OTU}_{95}$ relative distribution in the $16 \mathrm{~S}$ rRNA gene libraries. Triangles red A, B libraries, squares green A, B libraries, circles grey A, B libraries from the six clone libraries. Table 2 reports the percentages of sequence affiliation. Ten major bacterial phyla and two plastid lineages have been identified. Between $2 \%$ and $9 \%$ of the clones could only be classified as unknown bacteria, since they did not exhibit significant homology with any of the sequences deposited in the Ribosomal Database Project. The weathered area was colonized by an average of nine different families, while the vegetated area exhibited a significantly higher number, with an average of 26 bacterial families, similar to the surrounding moraines, containing an average of 24 families.

Phototrophs were significantly more abundant in the surrounding moraine rather than in the area affected by the weathered stone. Unidentified Cyanobacteria accounted up to $39 \%$ of the clones, while the green non-sulfur Chloroflexi reached $8 \%$ of the clones in GreenA library. On the contrary, Cyanobacteria in RedA and RedB were less than or equal to $4 \%$, and the libraries were dominated by Acidobacteria mainly belonging to the Acidobacteriaceae family (up to $38 \%$ of the clones) and Alphaproteobacteria of the family Acetobacteraceae (up to $33 \%$ of the clones). Between $17 \%$ and $30 \%$ of the clones belonging to the latter family were in particular affiliated to the genus Acidiphilium.

The vegetated area demonstrated the presence of a significant fraction of Cyanobacteria $(10 \%$ and $17 \%$ in GreenA and GreenB, respectively). Other abundant groups

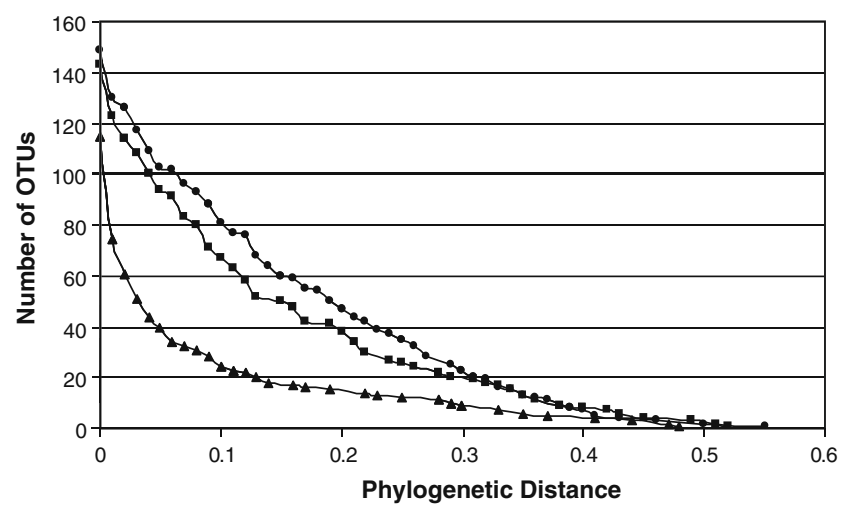

Figure 2 Lineage per time plots, calculated for each cumulative library containing the sequences obtained from the samples of each area. Triangle bioweathered area (RedA $4+\mathrm{RedB})$, square vegetated area $($ GreenA+GreenB), circles external moraine (GreyA+GreyB) 
Table 2 Phylogenetic identification of the clones from 16S rRNA libraries

\begin{tabular}{|c|c|c|c|c|c|c|c|c|c|c|c|c|c|}
\hline \multirow[t]{3}{*}{ Phylum and/or class } & \multicolumn{6}{|c|}{ Sites } & \multirow[t]{3}{*}{ Order and/or family and/or genus } & \multicolumn{6}{|c|}{ Sites } \\
\hline & \multicolumn{2}{|c|}{ Red } & \multicolumn{2}{|c|}{ Green } & \multicolumn{2}{|c|}{ Grey } & & \multicolumn{2}{|c|}{ Red } & \multicolumn{2}{|c|}{ Green } & \multicolumn{2}{|c|}{ Grey } \\
\hline & A & $\mathrm{B}$ & $\mathrm{A}$ & $\mathrm{B}$ & A & $\mathrm{B}$ & & $\mathrm{A}$ & $\mathrm{B}$ & A & $\mathrm{B}$ & A & $\mathrm{B}$ \\
\hline Bacteria unk & 4 & 2 & 7 & 7 & 8 & 9 & & & & & & & \\
\hline \multirow[t]{8}{*}{ Acidobacteria } & 38 & 37 & 4 & 3 & 6 & 2 & Acidobacteriaceae unk & & 1 & 1 & & 2 & \\
\hline & & & & & & & Acidobacteriaceae, Acidobacterium & 19 & 23 & & & & \\
\hline & & & & & & & Acidobacteriaceae, Gp 1 family & 19 & 12 & & & & \\
\hline & & & & & & & Acidobacteriaceae, Gp 3 family & & & & & 1 & \\
\hline & & & & & & & Acidobacteriaceae, Gp 4 family & & & 2 & 1 & 1 & 1 \\
\hline & & & & & & & Acidobacteriaceae, Gp 6 family & & & 1 & 2 & & \\
\hline & & & & & & & Acidobacteriaceae, Gp 7 family & & & & & 1 & \\
\hline & & & & & & & Acidobacteriaceae, Gp 10 family & & & & & & 1 \\
\hline \multirow{5}{*}{$\begin{array}{l}\text { Bacteroidetes, } \\
\text { Sphingobacteria }\end{array}$} & & & 19 & 2 & 19 & 6 & Sphingobacteriales unk & & & 11 & & 1 & 2 \\
\hline & & & & & & & Sphingobacteriales, Flexibacteraceae & & & 4 & 1 & 7 & \\
\hline & & & & & & & Sphingobacteriales, Crenotrichaceae & & & 3 & 1 & 8 & 3 \\
\hline & & & & & & & Sphingobacteriales, Saprospiraceae & & & & & 2 & \\
\hline & & & & & & & Sphingobacteriales, Sphingomonadaceae & & & & & 1 & \\
\hline Cyanobacteria & 4 & 1 & 10 & 17 & 28 & 39 & Cyanobacteria unk & 4 & 1 & 10 & 17 & 28 & 39 \\
\hline \multirow[t]{13}{*}{$\alpha$ Proteobacteria } & 30 & 34 & 18 & 24 & 13 & 24 & $\alpha$ Proteobacteria unk & & & 4 & 2 & 3 & \\
\hline & & & & & & & Rhodospirillales, Acetobacteraceae & & 16 & & & & 3 \\
\hline & & & & & & & $\begin{array}{l}\text { Rhodospirillales, Acetobacteraceae, } \\
\text { Acidiphilium }\end{array}$ & 30 & 17 & & & & \\
\hline & & & & & & & Rhizobiales unk & & 1 & 6 & 2 & 1 & 3 \\
\hline & & & & & & & Rhizobiales, Rhizobiaceae & & & 1 & & 1 & \\
\hline & & & & & & & Rhizobiales, Bradyrhizobiaceae & & & & 3 & & \\
\hline & & & & & & & Rhizobiales, Hypnomicrobiaceae & & & & 7 & 1 & 2 \\
\hline & & & & & & & Rhizobiales, Methylocystaceae & & 1 & & & & 1 \\
\hline & & & & & & & Sphingomonadales, Sphingomonadaceae & & & 4 & 4 & 6 & 12 \\
\hline & & & & & & & Rhodobacterales & & & 1 & 1 & 1 & 2 \\
\hline & & & & & & & Caulobacterales, Caulobacteraceae unk & & & & 1 & & \\
\hline & & & & & & & $\begin{array}{l}\text { Caulobacterales, Caulobacteraceae, } \\
\text { Brevundimonas }\end{array}$ & & & 1 & 2 & & \\
\hline & & & & & & & $\begin{array}{l}\text { Caulobacterales, Caulobacteraceae, } \\
\text { Phenylobacterium }\end{array}$ & & & & 1 & & \\
\hline \multirow[t]{8}{*}{$\beta$ Proteobacteria } & 4 & 1 & 14 & 23 & 4 & 8 & $\beta$ Proteobacteria unk & 4 & 1 & 2 & 3 & 2 & 1 \\
\hline & & & & & & & Burkholderiales unk & & & 1 & 3 & & 2 \\
\hline & & & & & & & Burkholderiales, Comamonadaceae & & & 4 & 6 & & 1 \\
\hline & & & & & & & Burkholderiales, Incertae sedis 5 & & & 6 & 10 & & 2 \\
\hline & & & & & & & Burkholderiales, Oxalobacteraceae & & & & 1 & & \\
\hline & & & & & & & Rhodocyclales, Rhodociclaceae & & & & & & 1 \\
\hline & & & & & & & Methylophilales & & & 1 & & & \\
\hline & & & & & & & Alcaligenaceae, Derxia & & & & & 2 & \\
\hline \multirow[t]{3}{*}{$\gamma$ Proteobacteria } & 1 & 6 & 6 & & 3 & & $\gamma$ Proteobacteria unk & & & 3 & & 1 & \\
\hline & & & & & & & Xanthomonadales, Xanthomonadaceae & 1 & 6 & & & 1 & \\
\hline & & & & & & & $\begin{array}{l}\text { Pseudomonadales, Pseudomonadaceae, } \\
\text { Pseudomonas }\end{array}$ & & & 2 & & 1 & \\
\hline \multirow[t]{4}{*}{$\delta$ Proteobacteria } & & & 3 & 4 & 4 & 2 & $\delta$ Proteobacteria unk & & & 3 & & 1 & 2 \\
\hline & & & & & & & Mixococcales unk & & & & 1 & & \\
\hline & & & & & & & Mixococcales, Polyangiaceae & & & & 3 & 1 & \\
\hline & & & & & & & Mixococcales, Cystobacteraceae & & & & & 2 & \\
\hline
\end{tabular}


Table 2 (continued)

\begin{tabular}{|c|c|c|c|c|c|c|c|c|c|c|c|c|c|}
\hline \multirow[t]{3}{*}{ Phylum and/or class } & \multicolumn{6}{|c|}{ Sites } & \multirow[t]{3}{*}{ Order and/or family and/or genus } & \multicolumn{6}{|c|}{ Sites } \\
\hline & \multicolumn{2}{|c|}{ Red } & \multicolumn{2}{|c|}{ Green } & \multicolumn{2}{|c|}{ Grey } & & \multicolumn{2}{|c|}{ Red } & \multicolumn{2}{|c|}{ Green } & \multicolumn{2}{|c|}{ Grey } \\
\hline & A & B & A & B & A & B & & A & $\mathrm{B}$ & A & B & A & B \\
\hline \multirow[t]{11}{*}{ Actinobacteria } & 7 & 6 & 6 & 4 & & 3 & Actinobacteria unk & 6 & 1 & & & & \\
\hline & & & & & & & $\begin{array}{l}\text { Acidimicrobiales, Acidimicrobiaceae, } \\
\text { Acidimicrobium }\end{array}$ & 1 & & & & & \\
\hline & & & & & & & Actinomycetales unk & & 3 & 1 & & & \\
\hline & & & & & & & Actinomycetales, Micrococcinaea & & & 1 & & & \\
\hline & & & & & & & Actinomycetales, Microbacteriaceae & & & 1 & & & \\
\hline & & & & & & & Actinomycetales, Actinosynnemantaceae & & & 1 & & & \\
\hline & & & & & & & Actinomycetales, Intrasporangiaceae & & & 1 & 1 & & \\
\hline & & & & & & & Actinomycetales, Nakamurellaceae & & 1 & & & & \\
\hline & & & & & & & Actinomycetales, Nocardioidaceae & & & & 1 & & 1 \\
\hline & & & & & & & Actinomycetales, Frankineae & & & & 2 & & \\
\hline & & & & & & & Rubrobacterales & & & & & & 2 \\
\hline Planctomycetacia & 1 & & 1 & & 1 & & Planctomycetales, Planctomycetaceae & 1 & & 1 & & 1 & \\
\hline \multirow[t]{4}{*}{ Chloroflexi } & & & 1 & & 8 & 1 & Choroflexaceae unk & & & & & 2 & \\
\hline & & & & & & & Chloroflexales, Chloroflexaceae, Roseiflexus & & & 1 & & 3 & \\
\hline & & & & & & & $\begin{array}{l}\text { Herpetosiphonales, Herpetosiphonaceae, } \\
\text { Herpetosiphon }\end{array}$ & & & & & 1 & \\
\hline & & & & & & & Caldineales, Caldilineacea, Caldilinea & & & & & 1 & 1 \\
\hline Gemmatimonadetes & & & & & & 4 & Gemmatimonadaceae, Gemmatimonas & & & & & & 4 \\
\hline Clostridia & & & 1 & & & & Clostridiales, Clostridiaceae, Clostridium & & & 1 & & & \\
\hline \multirow[t]{2}{*}{ Verrucomicrobiae } & & & 3 & 3 & 2 & & $\begin{array}{l}\text { Verrucomicrobiales, } \\
\text { Xiphinematobacteriaceae }\end{array}$ & & & 2 & & 2 & \\
\hline & & & & & & & Verrucomicrobiales, Opitutaceae & & & 1 & 3 & & \\
\hline Streptophyta unk & 6 & 9 & 7 & 11 & 2 & & & & & & & & \\
\hline Chlorophyta unk & 4 & 4 & & & & 1 & & & & & & & \\
\hline
\end{tabular}

unk unknown classification

in this area were alpha- and beta-subgroups of Proteobacteria (18-24\% and $14-23 \%$ of the clones, respectively). In the vegetated area, $\mathrm{pH}$ is around neutrality (7.1 \pm 0.3$)$ [13], Acetobacteraceae are absent, and Alphaproteobacteria are represented by different families like Rhizobiales, Sphingomonadales, and Caulobacterales. Betaproteobacteria are significantly higher in the vegetated BSC than in the adjacent ones, mainly represented by Burkholderiales. Sequences belonging to the Actinomycetales and Verrucomicrobiae taxonomic groups were quite exclusively found in the vegetated area (4-6\% and $3 \%$ of the clones, respectively).

\section{Nutrient Weathering and Iron-Oxidizing Bacteria Counts}

The area affected by pyritic stone weathering demonstrated very low $\mathrm{pH}$, up to 3.5 , and high reduced $\mathrm{Fe}^{2+}$ content, up to $60.8 \mathrm{mg} \mathrm{kg}^{-1} \mathrm{dm}$ [13]. The weathered rock was a conglomerate, embodying microcrystals of pyrite (Fig. 3a) and apatite (Fig. 3b) containing the essential mineral nutrients Fe, S, and $\mathrm{P}$, as revealed by SEM-EDX backscat- tering analyses. The release of these nutrients was demonstrated by the higher relative abundance of $\mathrm{Fe}, \mathrm{S}$, and $\mathrm{P}$ elements on the surface of BSC collected below the stone, with respect to the surrounding areas, as measured by ESEM microscopic analysis (Fig. 4c).

Iron-oxidizing bacteria were counted by most probable number in BSC downstream a second more extended pyritic rock, site BC-RC1 [13], along the bioweathered strip from 0.5 to $10 \mathrm{~m}$ distance from the rock. Iron oxidizers demonstrated a relatively high count below the rock $(4.3 \pm$ $3.7 \log _{10}$ ), progressively decreasing to $0.5 \pm 0.1 \log _{10}$ along with the increase of the distance from the stone (Fig. 4).

\section{Discussion}

The J-Libshuff analysis has been applied to compare the composition of bacterial communities colonizing the weathered area, the vegetated area, and the barren moraine. The results of $\int$-Libshuff analysis indicated that different 
Figure 3 Mineralogical analysis of rock and BSC surface. a, b SEM-EDX back scattering electron micrographs of thin-layer shiny sections of the rock. EDX analyses were performed in areas indicated by the arrows. c ESEM analysis of BSC collected on the horizontal transect A, $5 \mathrm{~cm}$ below the rock. Percentage of $\mathrm{Fe}, \mathrm{S}$, and $\mathrm{P}$ elements are reported for samples collected in the red weathered area in proximity of the rock, the green vegetated areas at the border, and the grey external moraine. The samples that were characterized also by 16S rRNA clone libraries are indicated a

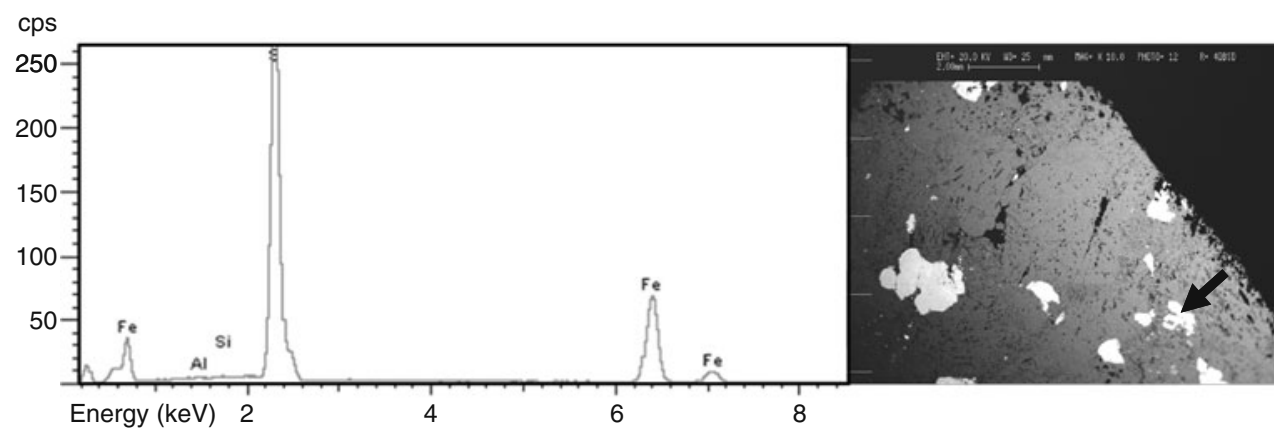

b

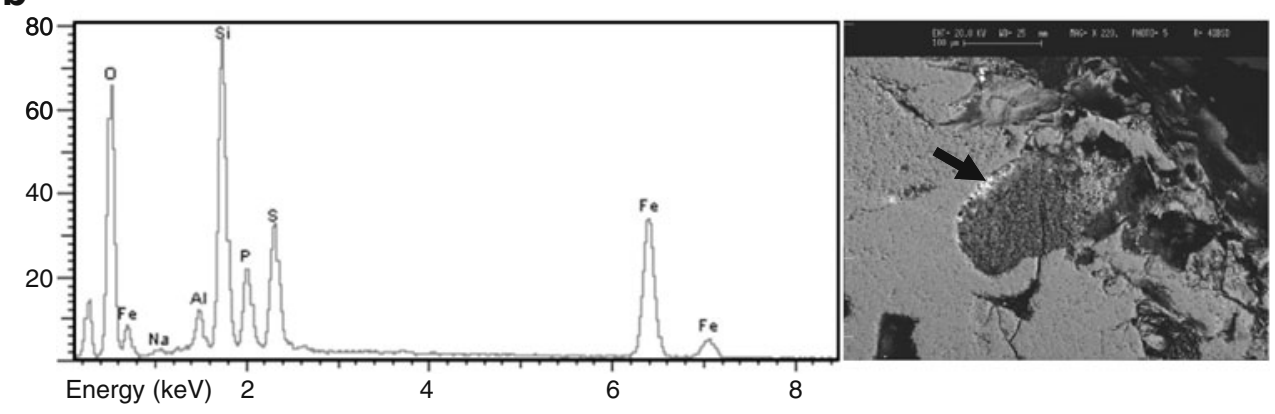

C

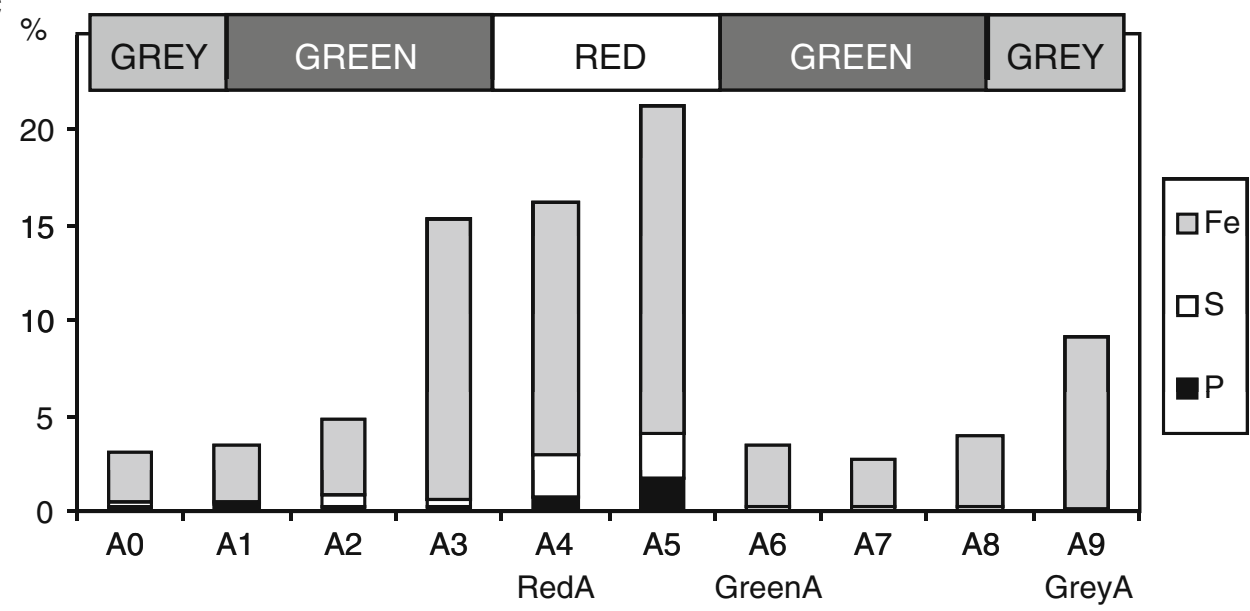

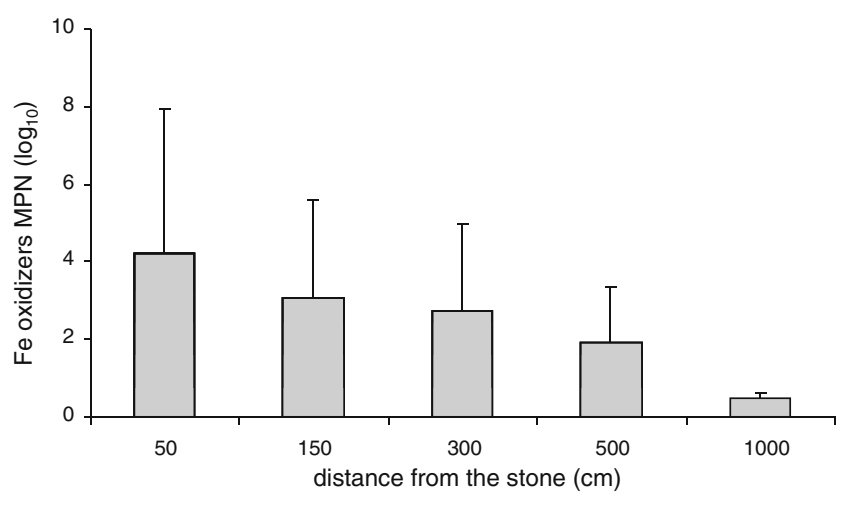

Figure 4 MPN counts of iron-oxidizing bacteria in the bioweathered area downstream the pyritic rock in the ML-RC1 site [13] environmental factors, triggered by the presence of the weathered stone, created different ecological niches, which selected a peculiar microbiota composed by bacteria belonging to few dominant taxa. The comparison of the replicated samples collected in each area showed that among the vegetated area and the surrounding moraine, the bacterial colonization of the BSC was highly heterogeneous. Only the samples collected from the weathered area were not significantly different, suggesting that in this niche, strong selecting forces induced the flourishing of specific adapted populations. Acidic $\mathrm{pH}$, as a consequence of pyrite oxidation, is the environmental parameter that mainly characterizes this area, reaching a value of $3.5 \pm 0.2$ below the stone [13]. This result is in accordance with previous findings that reported a strong correlation between soil $\mathrm{pH}$ and bacterial diversity [20]. The presence of strong 
selecting forces in weathered BSC is evident also from DCA analyses of $\mathrm{OTU}_{95}$ distribution, where both the libraries resulted well separated from the others (Fig. 1). The vegetated area and the surrounding moraine were more similar, being differentiated only on axis 1 of the DCA plot (Fig. 1). Young deglaciated moraines were reported to host unsuspected high bacterial diversity, probably due to a loss of competition in poorly developed environments [11], where fungal mycelia and plant roots are hampered by nutrient limitations and mechanical constrains like freeze and thaw cycles $[21,22]$. On the contrary, in developed soils, high diversity in substrate sources and interactions with plants and microfauna lead to high bacterial diversity indexes [23, 24]. Despite similar values of bacterial biodiversity, the vegetated BSC was colonized by peculiar phylogenetic groups, differentiated from the surrounding moraine (Fig. 1 and Table 2).

The phylogenetic composition of the microbiota that colonized the BSC of the three different areas has been described in detail by the screening of bacterial 16S rRNA clone libraries. While in the weathered area the low biodiversity permitted a high percentage of library coverage, in the vegetated area and in the barren moraine, only a fraction of the overall diversity was described (Table 1). The interpretation of differences among bacterial communities in the different sites could in principle be affected by the not exhaustive sampling of their phylogenetic diversity. Some correlations between community phylogenetic composition and environmental factors affecting the sites can be nevertheless found.

The abundance of bacterial families retrieved both in the vegetated area and in the barren moraine was almost three times higher than in the weathered area, confirming the occurrence of strong selective environmental conditions that limit the ability of many bacteria to colonize this habitat.

Between $92 \%$ and $100 \%$ of the 540 clones retrieved in all the libraries could be grouped within Gram-negative $\left(\mathrm{G}^{-}\right)$bacteria. $\mathrm{G}^{-}$-dominated communities have been interpreted as initial stages of ecosystem development [12], since many chemolithotrophic bacteria are $\mathrm{G}^{-}$. Tscherko et al. [12], basing on PLFA profiles, detected an increase in $\mathrm{G}^{+} / \mathrm{G}^{-}$ratio in the rhizosphere of Poa alpina during ecosystem development along a deglaciation chronosequence. The extremely low $\mathrm{G}^{+} / \mathrm{G}^{-}$ratio retrieved in the libraries would suggest that chemolithotrophy is an important energy metabolism in all the three areas of the site, estimated to be released from ice cover only 27 years ago [13]. The high percentage of Cyanobacteria and Chloroflexi detected in the barren moraine libraries is consistent with previous findings that reported photoautotrophic bacteria, and particularly Cyanobacteria, as the pioneer organisms in BSC of developing terrestrial ecosystems [25]. They are typical of arctic soils and were detected with high prevalence along all the chronosequence in the Midtre Lovénbreen moraines up to 2,000 years of soil development out of ice cover [3]. Cyanobacteria can exploit sunlight to fix atmospheric carbon and nitrogen, having a key role during the first colonization stages by providing nutrients to the heterotrophic populations, increasing soil $\mathrm{pH}$ due to photosynthesis and increasing soil properties like water retention, essential for plant establishment.

Above the weathered stone nevertheless, a second autotrophic metabolism has been identified, mediated by A. ferrooxidans, having a key role in establishing acidity with consequent fertility gradients and plant flourishing [13]. Iron-sulfur oxidizing bacteria were counted in the BSC of ML-RC1 weathered site, and their number decreased along with the increase of the distance from the stone, demonstrating their involvement in rock bioweathering (Fig. 4). Moreover, pyrite and apatite were retrieved in the weathered stone, source of mineral nutrients like $\mathrm{P}, \mathrm{Fe}$, and $\mathrm{S}$ that were demonstrated to occur in higher abundance in the BSC downstream the rock, contributing to the creation of fertility gradients (Fig. 3). Rock weathering occurred by the release in the soil above the stone of Fe and $\mathrm{S}$ from pyrite crystals, as the result of iron-sulfur oxidation, and $\mathrm{P}$ from apatite crystals, due to the strong acidification occurring from pyrite bioleaching.

The phylogenetic taxa that mainly colonize the weathered area belong to Acidobacteria and Alphaproteobacteria of the family Acetobacteraceae. These groups are typically found in acidic environments [26, 27], consistently with the low $\mathrm{pH}$ of the area affected by $A$. ferrooxidans iron-sulfur oxidation. In the weathered area, $17-30 \%$ of total clones belong to the genus Acidiphilium, hypothesized to be in a commensal association with $A$. ferrooxidans, acting as scavenger of the pyruvate excreted by the latter species [28].

Despite the cultivation of iron-oxidizing bacteria, responsible for the chemolithoautotrophic metabolism detected in the weathered area, 16S rRNA clone libraries did not reveal the presence of $A$. ferrooxidans in the weathered area, but this could be expected, considering that iron oxidation is one of the less energy-gaining metabolisms [29]. A. ferrooxidans was hence present in the stone weathered area under the detection limit of the method, but despite low abundance had high pyrite oxidation activity as demonstrated by low $\mathrm{pH}$ values.

The microbiota inhabiting the vegetated area was primarily represented by taxa normally found in mature soils like Rhizobiales, Sphingomonadales, and Caulobacterales [30]. Rhizobiales are of particular interest since they comprise many $\mathrm{N}$ fixers that can have, in parallel with Cyanobacteria, a primary role in the $\mathrm{N}$ cycle. Moreover, several clones were affiliated to the families Rhizobiaceae and Bradyrhizobia- 
ceae, known to establish symbiotic relations with plants. Among Betaproteobacteria, we found a high prevalence of bacteria belonging to the order Burkholderiales. This order, and especially the family Comamonadaceae, was retrieved in several glacial environments like ice cores [31], permanent lake ice [32], and deglaciated soil along moraine chronosequences in the first and medium stages of development [9]. Nemergut et al. [9] hypothesized that Comamonadaceae are typical populations of ice environment, that during deglaciation are seeded in the developing soil, decreasing in relative abundance along with soil age. Only in the vegetated area, we detected also the occurrence of Actinomycetales and Verrucomicrobiae, known as typical soil microbiota [33, 34]. Verrucomicrobia, Bacteroidetes, and Acidobacteria were found in late successional stages of ecosystem development on the foreland of Puca glacier (Peruvian Andes) and were considered proxy of old soil microbiota [9]. Moreover, Verrucomicrobia and Acidobacteria, known to be among the soil bacterial groups with the lower cultivability levels, can indicate a shift from $r$ to $K$ growth strategy along with soil age and development and increase of carbon sources complexity, yet described in Puca glacier [9] and in Dammaglacier (Switzerland) [10] forelands. Bacterial succession and development of soil ecosystem along with time after ice retreat have been reported in several glacier forefronts $[7,9,35]$.

The results obtained in the present work confirmed and detailed what was previously described by Borin et al. [13], showing that in ecological niches with the same age out of ice covering, at the border between chemolithotrophic- and phototrophic-based autotrophic metabolisms, enhanced ecosystem development took place. The age-independent interaction of these microbial metabolisms increased here the availability of nutrients with the effect of triggering soil development and plant biocoenosis. The synergy between these two bacterial autotrophic processes in favoring microorganism and plant colonization is probably not restricted to the Midtre Lovénbreen glacier foreland but should be explored in other Fe(II)-rich environments. The analytical 16S rRNA gene library survey carried out in the present work demonstrated that the microbial weathering of a pyritic rock favored only few acid-loving bacterial taxa in the soil crust in close proximity of the rock. Less than $40 \mathrm{~cm}$ apart, in parallel with the increase in $\mathrm{pH}$, the bacterial phylogenetic biodiversity in the soil crust increased, with the selection of a more complex microbial community, typical of soil and rhizosphere, with a key role in the formation of a plant oasis.

Acknowledgments The authors thank the Earth and Environment Department of CNR for the use of "Dirigibile Italia" Station in Ny-Ålesund, Svalbard, and Ev-K2-CNR committee for supporting the project "Study of primary colonisation and soil neogenesis mechanisms in deglaciating environments at high altitude and low latitude."

\section{References}

1. Begon M, Harper JL, Townsend CR (1996) Ecology: individuals, populations and communities. Blackwell Science, Cambridge

2. Bashan Y, Li C, Lebsky VK, Moreno M, de-Basjan LE (2002) Primary colonisation of volcanic rocks by plants in arid Baja California, Mexico. Plant Biol 4:392-402

3. Hodkinson ID, Coulson SJ, Webb NR (2003) Community assembly along proglacial chronosequences in the high Arctic: vegetation and soil development in north-west Svalbard. J Ecol 91:651-663

4. Adams JB, Palmer F, Staley JT (1992) Rock weathering in deserts: mobilisation and concentration of ferric iron by microorganisms. Geomicrobiol J 10:99-114

5. Illmer C, Barbato A, Schinner F (1995) Solubilisation of hardly soluble $\mathrm{AlPO}_{4}$ with $\mathrm{P}$-solubilising microorganisms. Soil Biol Biochem 27:265-270

6. Fizharris BB (1996) The cryosphere: changes and their impact. In: Houghton JT, Filho LGM, Callander BA, Harris N, Kattenberg A, Maskell K (eds) Climate change 1995: the science of climate change. Cambridge University Press, Cambridge, pp 241-265

7. Schutte UME, Abdo A, Bent SJ, Williams CJ, Schneider GM, Solheim B, Forney LJ (2009) Bacterial succession in a glacier foreland of the high arctic. ISME J 3:1258-1268

8. Deiglmayr K, Philippot L, Tscherko D, Kandeler E (2006) Microbial succession of nitrate-reducing bacteria in the rhizosphere of $\mathrm{Poa}$ alpina across a glacier foreland in the Central Alps. Environ Microbiol 8:1600-1612

9. Nemergut DR, Anderson SP, Cleveland CC, Martin AP, Miller AE, Seimon A, Schmidt SK (2007) Microbial community succession in an unvegetated, recently deglaciated soil. Microb Ecol 53:110-122

10. Sigler VW, Crivii S, Zeyer J (2002) Bacterial succession in glacial forefield soils characterized by community structure, activity and opportunistic growth dynamics. Microb Ecol 44:306-316

11. Sigler WV, Zeyer J (2002) Microbial diversity and activity along the forefields of two receding glaciers. Microb Ecol 43:397-407

12. Tscherko D, Hammesfahr U, Marx M-C, Kandeler E (2004) Shifts in rhizosphere microbial communities and enzyme activity of Poa alpina across an alpine chronosequence. Soil Biol Biochem 36:1685-1698

13. Borin S, Ventura S, Tambone F, Mapelli F, Schubotz F, Brusetti L, Scaglia B, D'Aqui L, Solheim B, Turicchia S, Marasco R, Hinrichs K-U, Baldi F, Adani F, Daffonchio D (2009) Rock weathering creates oasis of life in a high Arctic desert. Environ Microbiol 12:293-303

14. Silverman MP, Lundgren DG (1959) Studies on the chemoautotrophic iron bacterium Ferrobacillus ferrooxidans: I. An improved medium and a harvesting procedure for securing high cell yields. J Bacteriol 77:642-647

15. Thompson JD, Gibson TJ, Plewniak F, Jeanmougin F, Higgins DG (1997) The ClustalX windows interface: flexible strategies for multiple sequence alignment aided by quality analysis tools. Nucleic Acids Res 24:4876-4882

16. Schloss PD, Westcott SL, Ryabin T, Hall JR, Hartmann M, Hollister EB, Lesniewski RA, Oakley BB, Parks DH, Robinson CJ, Sahl JW, Stres B, Thallinger GG, Van Horn DJ, Weber CF (2009) Introducing mothur: open-source, platform-independent, community-supported software for describing and comparing microbial communities. Appl Environ Microbiol 75:7537-7541

17. Jackson J (1991) A user's guide to principal components. Wiley, New York

18. Hammer $\varnothing$, Harper DAT, Ryan PD (2001) PAST: paleontological statistics software package for education and data analysis. Palaeontol Electronica 4:1

19. Singleton DR, Furlong MA, Rathbun SL, Whitman WB (2001) Quantitative comparisons of $16 \mathrm{~S}$ rDNA sequence libraries from environmental samples. Appl Environ Microbiol 67:4373-4376 
20. Fierer N, Jackson (2006) The diversity and biogeography of soil bacterial communities. Proc Natl Acad Sci USA 103:626-631

21. Jumpponen A (2003) Soil fungal community assembly in a primary successional glacier forefront ecosystem as inferred from rDNA sequence analyses. New Phytol 158:569-578

22. Ohtonen R, Fritze H, Pennanen T, Jumpponen A, Trappe J (1999) Ecosystem properties and microbial community changes in primary succession on a glacier forefront. Oecologia 119:239-246

23. Shrestha PM, Noll M, Liesak W (2007) Phylogenetic identity, growth-response time and rRNA copy number of soil bacteria indicate different stages of community succession. Environ Microbiol 9:2464-2474

24. Tarlera S, Jangid K, Ivester AH, Whitman WB, Williams MA (2008) Microbial community succession and bacterial diveristy in soils during 77000 years of ecosystem development. FEMS Microbiol Ecol 64:129-140

25. Belnap J, Budel B, Lange OL (2001) Biological soil crusts: characteristics and distribution. In: Belnap J, Lange OL (eds) Biological soil crusts: structure, function, and management. Springer, Berlin, pp 3-30

26. Bilgin AA, Silverstain J, Jenkins JD (2004) Iron respiration by Acidiphilium cryptum at pH 5. FEMS Microbiol Ecol 49:137-143

27. Mannisto MK, Tiirola M, Haggblom MM (2007) Bacterial communities in Arctic fjelds of Finnish Lapland are stable but highly pH-dependent. FEMS Microbiol Ecol 59:452-465
28. Harrison AP Jr (1984) The acidophilic thiobacilli and other acidophilic bacteria that share their habitat. Annu Rev Microbiol 38:265-292

29. Konhauser K (2007) Introduction to geomicrobiology. Blackwell Science, UK

30. Haichar FZ, Marol C, Berge O, Rangel-Castro JI, Prosser JI, Balesdent J, Heulin T, Achouak W (2008) Plant host habitat and root exudates shape soil bacterial community structure. ISME J 2:1221-1230

31. Sheridan PP, Miteva VI, Brenchley JE (2003) Phylogenetic analysis of anaerobic psycrophilic enrichment cultures obtained from a Greenland glacier ice core. Appl Environ Microbiol 69:2153-2160

32. Gordon DA, Priscu J, Giovannoni S (2000) Origin and phylogeny of microbes living in permanent Antarctic lake ice. Microb Ecol 39:197-202

33. Felske A, Akkermans ADL (1998) Prominent occurrence of ribosomes from an uncultured bacterium of the Verrucomicrobiales cluster in grassland soils. Lett Appl Microbiol 26:219-223

34. Williamson N, Brian P, Wellington EMH (2001) Molecular detection of bacterial and streptomycete chitinases in the environment. Antoine van Leeuwenhoek 78:315-321

35. Noll M, Wellinger M (2008) Changes of the soil ecosystem along a receding glacier: testing the correlation between environmental factors and bacterial community structure. Soil Biol Biochem 40:2611-2619 